\title{
Sentinel-2 Reveals Abrupt Increment of Total Suspended Matter While Ever Given Ship Blocked the Suez Canal
}

\author{
Milad Niroumand-Jadidi *(D) and Francesca Bovolo (D) \\ Fondazione Bruno Kessler, Digital Society Center, 38123 Trento, Italy; bovolo@fbk.eu \\ * Correspondence: mniroumand@fbk.eu
}

Citation: Niroumand-Jadidi, M.;

Bovolo, F. Sentinel-2 Reveals Abrupt Increment of Total Suspended Matter While Ever Given Ship Blocked the Suez Canal. Water 2021, 13, 3286. https://doi.org/10.3390/ w13223286

Academic Editors: Hongbin Liu and Domenico Cicchella

Received: 7 October 2021

Accepted: 17 November 2021

Published: 20 November 2021

Publisher's Note: MDPI stays neutral with regard to jurisdictional claims in published maps and institutional affiliations.

Copyright: (C) 2021 by the authors. Licensee MDPI, Basel, Switzerland. This article is an open access article distributed under the terms and conditions of the Creative Commons Attribution (CC BY) license (https:/ / creativecommons.org/licenses/by/ $4.0 /)$.

\begin{abstract}
The blockage of the Suez Canal, one of the world's key trade routes, by a giant container ship in March 2021 was in the spotlight of news media worldwide, mainly because of its economic impacts. In this study, we look at this event from an environmental perspective by analyzing the impact of the artificial barrier made by the ship over the channel and of operations like dredging on the concentration of total suspended matter (TSM). In this context, multitemporal Sentinel-2 images are used to study short-term variations of TSM within a time window spanning before, during, and after the blockage event. A well-established neural network-based processor called Case 2 Regional CoastColour (C2RCC) is employed to derive remote sensing reflectance (Rrs) and then TSM concentrations from Sentinel-2 imagery. The results indicate that the stuck ship acted as an artificial barrier leading to very different TSM conditions north and south of the canal. Furthermore, the blockage of the Suez Canal and subsequent dredging caused an abrupt increment $(+400 \%)$ in the concentration of TSM moving north from the ship's location. We also identified a very high contrast between the TSM concentration in the north and south of the vessel during the blockage event.
\end{abstract}

Keywords: water quality; Suez Canal; canal blockage; container ship; Sentinel-2; time-series; total suspended matter

\section{Introduction}

The Suez Canal was blocked by the giant Ever Given container ship that ran aground on 23 March 2021. Sandstorms and thus high winds and reduced visibility were the causes. This giant ship lodged diagonally on the southern part of the Suez Canal, one of the world's busiest shipping lanes. The accident grabbed the attention of global media due to its significant impact on world trade [1]. However, the accident had other consequences as well. In this study, we investigate an unexplored aspect of the Suez Canal blockage, which is concerned with the impact on water quality. This investigation is motivated by the fact that the giant Ever Given ship (with a length of $400 \mathrm{~m}$ and a weight of $200 \mathrm{k}$ tons) acted as an artificial and temporal barrier dividing the channel into two northern and southern parts. This barrier affects the natural water surface and subsurface processes. Further, the rescue operations, such as dredging, inserted an unusual load of sands and mud into the water. We perform multitemporal analyses using Sentinel-2 imagery to illustrate the impact of this event on the concentration of total suspended matter (TSM). TSM refers to organic and mineral suspended solids in the water column [2]. Increased TSM reduces the light penetration in the water column and thus the benthic habitat availability [3]. The spatiotemporal monitoring of TSM can contribute to studies of sediment transportation, water quality assessment, and management [2,4]. The Suez Canal and bay are one of Egypt's central fisheries, drinking, and irrigation resources. Thus, TSM concentration primarily impacts the ecosystem services provided by the canal [5-7].

Multispectral instruments (MSIs) onboard Sentinel-2A (2015) and Sentinel-2B (2017) provide appropriate radiometric sensitivity (12-bit) to the variations of water-leaving radiance due to changes in constituents $[8,9]$. Owing to the high radiometric resolution of 
Sentinel-2 MSI imagery along with high spectral (13 bands) and high spatial resolutions $(10-20 \mathrm{~m})$, there is a rapidly growing trend in the application of this imagery in studying inland and coastal waters [10-13].

There are various methods for the estimation of water quality parameters, including TSM from optical imagery. The methods can be categorized into two groups: (i) empirical methods that rely on regression analyses to build a relation between spectra-derived features and in situ measured values of the parameter of interest, such as TSM [14-16]; and (ii) physics-based methods, which are built upon inverting a radiative transfer model. In considering the former, a wide range of statistical and machine learning regressors are employed $[17,18]$. The empirical methods are straightforward to apply but require representative in situ data for training the regression models $[19,20]$. This limits the application of empirical techniques, especially those dealing with multitemporal analyses and remote areas, as in situ data becomes difficult or impossible to collect. In considering the latter, physical models are considered to formulate the interaction of light with atmosphere, water surface, water column, as well as substrate in the case of optically-shallow waters [21-25]. There are different physics-based approaches, such as look-up tables (LUTs), neural networks, and analytical spectrum matching. LUT approaches select for each image pixel the water constituents corresponding to the best-matching spectrum from the database of radiative transfer simulations of reflectance spectra that were pre-calculated using radiative transfer simulations [26]. Neural networks, such as those applied in Case 2 Regional CoastColour (C2RCC) algorithm [27], are trained using LUTs and can be used to estimate constituents. Analytical models invert a measured spectrum with physical models such as those implemented in the Water Color Simulator (WASI) [21]. In this study, we rely on the C2RCC processor to derive the concentration of TSM without the need for in situ data.

The main objective of the study is to analyze the impact of the Suez Canal blockage and associated dredging operations on the relative changes of TSM using multitemporal Sentinel-2 imagery. We analyze the images before, during, and after the event to observe the variations of TSM that impact the ecosystem services provided by the canal. Section 2 describes the C2RCC method used for TSM retrieval. The study area and the dataset are introduced in Section 3. Section 4 provides the results and discussion. Finally, concluding remarks are made in Section 5.

\section{Method}

The main goal of our study is to detect any anomaly change in the water quality in terms of TSM concentration during the Suez Canal blockage. This study relies on a physics-based approach called Case 2 Regional CoastColour (C2RCC) that can be applied without training data [27]. However, any reliable method can be used to retrieve the TSM concentration. The C2RCC processor involves two independent components of atmospheric and in-water parts. The atmospheric part inverts the top-of-atmosphere (TOA) radiance to water-leaving radiance. Then, the in-water component inverts the surface spectra to the inherent optical properties (IOPs) of the water column. The inversions are based upon a set of neural networks. An extensive database ( $\sim 5$ million) of water-leaving and TOA radiances simulated by a radiative transfer model in a range of IOPs is used for training the networks. Five IOPs are varied to perform the radiative transfer simulations, which include pigment absorption $\left(a_{\text {pig }}\right)$, absorption of detritus $\left(a_{d e t}\right)$, colored dissolved organic matter absorption $\left(a_{C D O M}\right)$, scattering of white particles $\left(b_{\text {wit }}\right)$ characterized by calcareous sediments, and typical sediment scatter $\left(b_{\text {part }}\right)$. Two different in-water conditions are assumed for the IOPs: (i) normal condition (C2RCC-N), where all of the mentioned IOPs vary in a standard range (e.g., absorption of CDOM at $443 \mathrm{~nm} a_{C D O M}<1 \mathrm{~m}^{-1}$ ), and (ii) extreme condition (C2RCC-E), where IOPs span over a vast range, including extreme conditions (e.g., $a_{C D O M}<60 \mathrm{~m}^{-1}$ ). The ranges of IOPs are reported in Table 1. In this study, we rely on the C2RCC-N, as the range of its IOPs is well suited to our case study. 
Table 1. The range of IOPs considered in training C2RCC neural networks.

\begin{tabular}{ccc}
\hline IOPs & C2RCC-N & C2RCC-E \\
\hline$a_{\text {pig }}\left[\mathrm{m}^{-1}\right]$ & {$[\sim 0,5.3]$} & {$[\sim 0,51]$} \\
$a_{\text {det }}\left[\mathrm{m}^{-1}\right]$ & {$[\sim 0,5.9]$} & {$[\sim 0,60]$} \\
$a_{C D O M}\left[\mathrm{~m}^{-1}\right]$ & {$[\sim 0,1]$} & {$[\sim 0,60]$} \\
$b_{\text {part }}\left[\mathrm{m}^{-1}\right]$ & {$[\sim 0,60]$} & {$[\sim 0,590]$} \\
$b_{\text {wit }}\left[\mathrm{m}^{-1}\right]$ & {$[\sim 0,60]$} & {$[\sim 0,590]$} \\
\hline
\end{tabular}

The retrieved IOPs are converted to the concentration of constituent by applying conversion factors. The TSM estimation involves scaling factors for $b_{\text {part }}$ and $b_{\text {wit }}$ termed as $f_{\text {bpart }}$ and $f_{\text {bwit }}$, respectively (Equation (1)).

$$
\mathrm{TSM}=b_{\text {part }} \times f_{b_{\text {part }}}+b_{\text {wit }} \times f_{b_{\text {wit }}}
$$

Since the Suez Canal is connected to the coastal waters, we consider the default values of conversion factors as representative of such in-water conditions. Possible differences between the default and site-specific values do not affect our analyses since we are interested in relative changes of TSM rather than its absolute values. C2RCC has been widely used in previous studies to derive water quality parameters. For instance, it provided promising results through the estimation of constituents in Baltic lakes using Sentinel-2 images [2]. C2RCC has also been employed for the generation of standard European Space Agency (ESA) Case-2 water products from Sentinel-3 (OLCI) imagery [27].

\section{Study Area and Dataset}

The Suez Canal is an artificial waterway that connects the Mediterranean Sea to the Red Sea. It is one of the world's busiest trade routes, with about $12 \%$ of total global trade moving through it [28]. The giant Ever Given container ship ran aground on 23 March 2021 and blocked the southern part of the canal diagonally. This accident was due to the storms and low visibility that occurred in the area. The blockage of the canal caused a large traffic jam and appeared vastly in the news. A variety of operations were carried out to free the container ship involving tugboats and dredging. After about a six-day blockage of the canal, the operations were successful in freeing the ship. It is estimated that the dredgers removed about $15,000-20,000 \mathrm{~m}^{3}$ of sand and mud from the ship's bow to allow the vessel to float in the Suez Canal [1]. Removal of this massive amount of sediment and mud affected the concentration of TSM in the water, and the changes to the concentration of TSM is investigated in this study. It was expected that the enormous body of the ship (400 $\mathrm{m}$ in length and $200 \mathrm{k}$ tons in weight) would have affected the natural flow of the water and all the water surface and subsurface processes. Thus, we aimed to investigate the impacts of the Suez Canal blockage and consequent dredging operations on the concentration of TSM in the water, which can impact canal ecosystem services like fisheries, drinking, and agricultural water supply [7].

In total, seven multitemporal Sentinel-2 images were considered in order to investigate the impact of the canal blockage on the TSM concentrations. The images span the time before, during, and after the blockage event (Table 2). Given the relatively narrow crosssectional width of the Suez Canal ( 200 m), ocean color sensors like Ocean and Land Color Instrument (OLCI) onboard Sentinel-3 are not appropriate for our analyses due to the coarse spatial resolution $(300 \mathrm{~m})$. Samples of the images are shown in Figure 1. The subset images also show the traffic jam during and shortly after the blockage event (Figure 1). 
Table 2. The list of Sentinel-2 imagery spanning the time before (blue), during (red), and after (green) the Suez Canal blockage.

\begin{tabular}{ccc}
\hline 23 January 2021 & 22 February 2021 & 19 March 2021 \\
\hline 29 March 2021 & 3 April 2021 & 8 April 2021 \\
\hline 13 April 2021 & & \\
\hline
\end{tabular}

19 March 2021

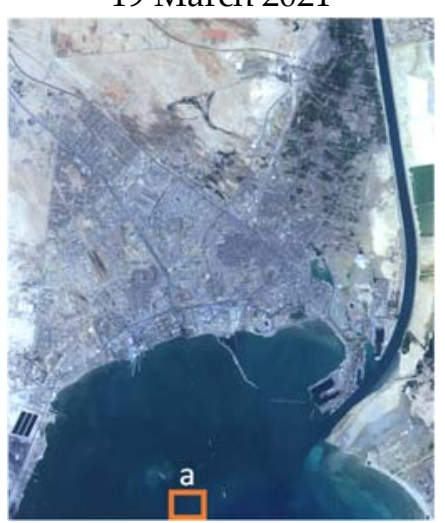

29 March 2021

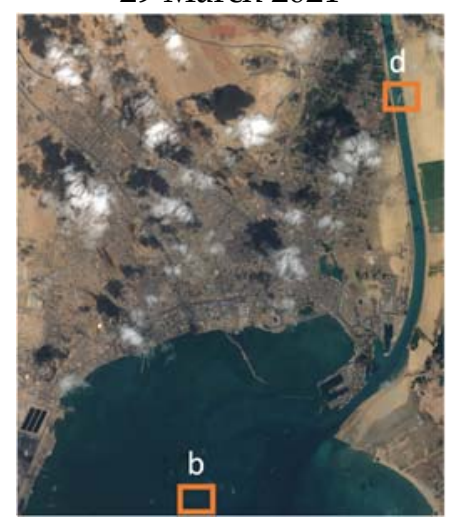

3 April 2021

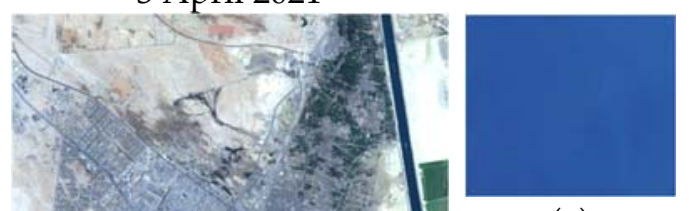

(a)

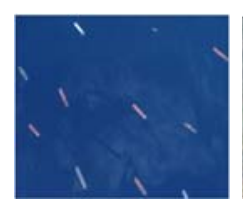

(c)

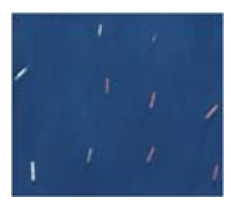

(b)

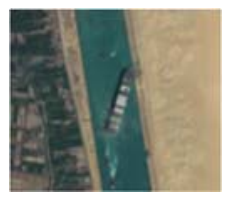

(d)

Figure 1. Multitemporal Sentinel-2 imagery of the southern part of the Suez Canal before, during, and after the ship blockage. Image subsets $(\mathbf{a}-\mathbf{d})$ show the location of the stuck ship and also the traffic jam.

\section{Results and Discussion}

The multitemporal TSM maps derived from C2RCC inversion of Sentinel-2 imagery are shown in Figure 2. The maps show that in the southern part of the canal, the TSM concentration was subject to variation, which was expected due to the region's relatively dynamic environment, mainly caused by the tidal effects from the connected sea. The study's key finding is that during the blockage event (29 March 2021), the stuck ship divided the canal into two TSM conditions. In this context, going northward from the location of the stuck ship, extremely high TSM concentrations were observed. This finding shows that the enormous body of the ship created a sort of artificial barrier leading to two very different in-water conditions in terms of TSM concentration. The extremely high concentration of TSM (up to $\sim 30 \mathrm{~g} / \mathrm{m}^{3}$ ) in the canal's northern section during the blockage event can be linked to the dredging operation that had been digging out sand and mud from under the bow of the ship. The concentration of the TSM after movement of the ship dropped to normal conditions $\left(\sim 5 \mathrm{~g} / \mathrm{m}^{3}\right)$, with no significant difference in the two segments of the canal separated by the ship during the blockage event. The TSM concentration in the section of the canal south of the location of the stuck ship during the blockage event was observed to be comparable with conditions before the event (19 March). This can be attributed to the free connection of the channel's lower part with the Red Sea, whereas the ship hinders the flow and exchange of water in the northern section.

Figure 3 shows the average TSM concentration over the investigated period and separately for the northern and southern sections of the canal from the point that the ship was stuck. An abrupt increment (on the order of 4 times) in the TSM concentration can be observed north of the ship's location during the canal blockage event (29 March). After that, the TSM concentration returns to the normal condition, as identified by the TSM retrieval from the first Sentinel-2 image available after removal of the ship (3 April). A high contrast can be observed between the TSM concentrations in the north and south sections of the canal at the point in which the ship was stuck (i.e., a 1.6 times higher concentration in the northern section) (Figures 2 and 3). 


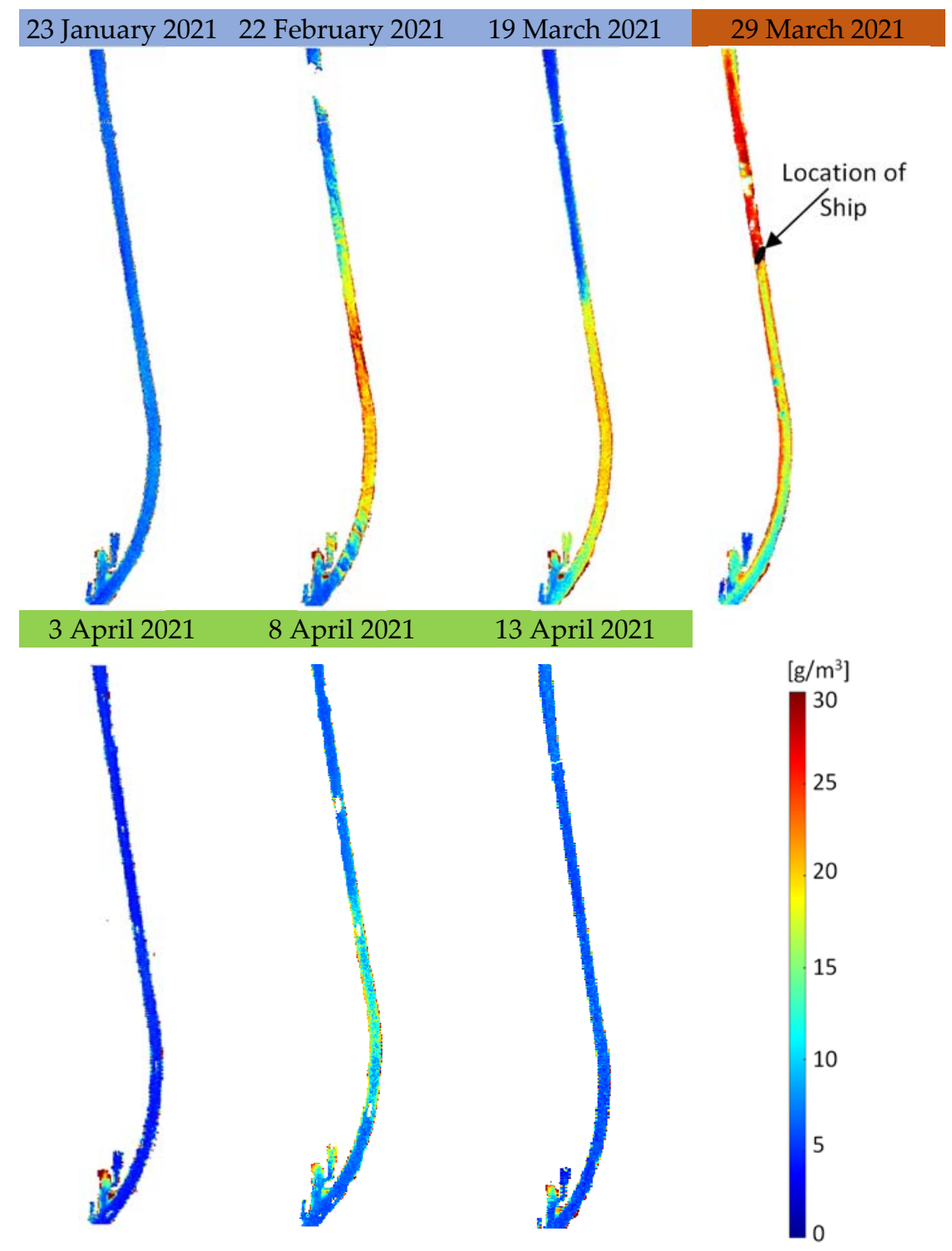

Figure 2. Multitemporal TSM maps of the Suez Canal derived from Sentinel-2 imagery before (blue), during (red), and after (green) the canal blockage event.

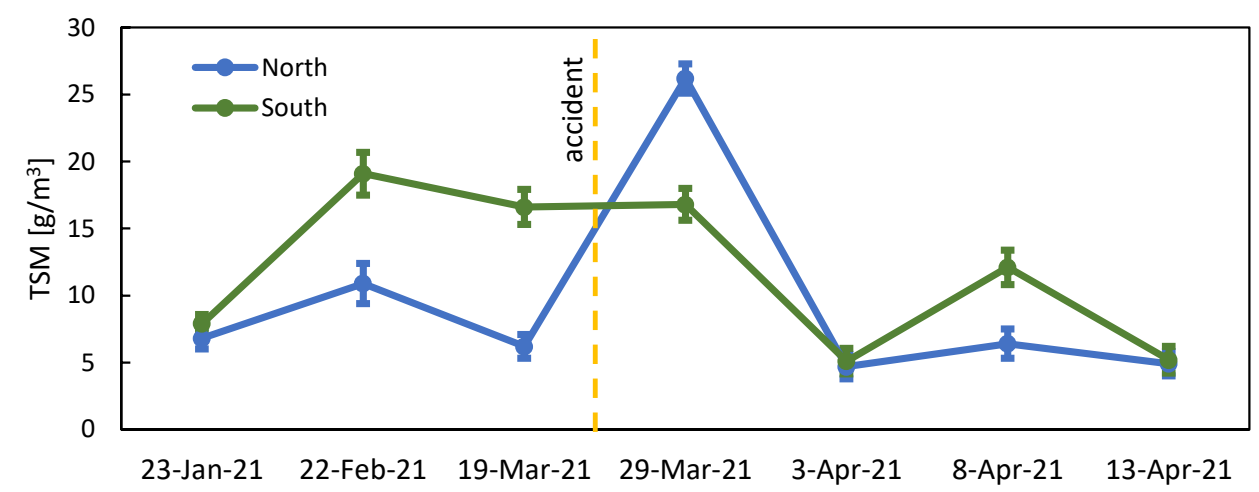

Figure 3. The average concentration of TSM north and south of the location of the stuck ship over the investigated period. The bars show the standard deviation of TSM concentration. 


\section{Conclusions}

The blockage of the Suez Canal was in the spotlight of news media for more than a week but with no specific attention to the possible effects on the in-water bio-optical conditions. In this study, we investigated the spatiotemporal variations of TSM concentrations derived from Sentinel-2 imagery over a period spanning from before to after the blockage event. The TSM retrievals are based on the well-established C2RCC method, which relies on the inversion of radiative transfer simulations by means of neural networks. The results indicate that the stuck ship acted as an artificial barrier, leading to a considerable contrast between the TSM concentrations north and south of the ship's location. This finding shows that the massive body of the vessel significantly reduced the surface and subsurface water flow between the upper and lower parts of the channel from the point at which the ship was stuck. This effect might be an area of interest for hydraulic analysts and aquatic navigation managers in order to better understand the impact of such giant vessels in waterways. Furthermore, the Sentinel- 2 retrievals revealed a very high increment of TSM in the northern section of the channel when the canal was blocked. This high TSM concentration can be attributed to the dredging operations removing a large amount of sand and mud. Thus, the concentration of TSM was increased on the order of four times in the northern section of the canal with respect to the normal conditions before and after the blockage event. The stuck ship also led to a TSM contrast on the order of 1.6 times between northern and southern sections of the canal.

Although the default C2RCC conversion factors are expected to be representative of the studied coastal environment, the absolute TSM values can be retrieved more accurately considering the site-specific IOPs. However, the investigation of relative TSM changes in this study is not affected by the conversion factors. Being independent of in-situ data expands the utility of remote sensing techniques to analyze unexpected events such as the Suez Canal blockage for which planning field data acquisition is not feasible. The accuracy assessment of the absolute TSM values in the Suez Canal could represent an area of investigation for future studies. Our work may also encourage future hydrodynamic studies to further investigate the sediment transportation processes during such events under different conditions (e.g., tidal effects).

Author Contributions: Conceptualization: M.N.-J. and F.B.; methodology: M.N.-J.; software: M.N.-J.; validation: M.N.-J.; formal analysis: M.N.-J.; investigation: M.N.-J.; resources: M.N.-J. and F.B.; data curation: M.N.-J.; writing—original draft preparation: M.N.-J.; writing—review and editing: M.N.-J. and F.B.; visualization: M.N.-J.; supervision: F.B. All authors have read and agreed to the published version of the manuscript.

Funding: This research received no external funding.

Data Availability Statement: The Sentinel-2 images are freely available at https: / /scihub.copernicus.eu/ (accessed on 10 August 2021).

Conflicts of Interest: The authors declare no conflict of interest.

\section{References}

1. CNN. Authorities Need to Remove up to 706,000 Cubic Feet of Sand to Free the Ever Given-CNN. Available online: https: //edition.cnn.com/2021/03/25/middleeast/suez-canal-ship-sand-intl-hnk/index.html (accessed on 22 April 2021).

2. Soomets, T.; Uudeberg, K.; Jakovels, D.; Brauns, A.; Zagars, M.; Kutser, T. Validation and comparison of water quality products in baltic lakes using sentinel-2 msi and sentinel-3 OLCI data. Sensors 2020, 20, 742. [CrossRef] [PubMed]

3. DeLuca, N.; Zaitchik, B.; Curriero, F. Can Multispectral Information Improve Remotely Sensed Estimates of Total Suspended Solids? A Statistical Study in Chesapeake Bay. Remote Sens. 2018, 10, 1393. [CrossRef]

4. Nechad, B.; Ruddick, K.G.; Park, Y. Calibration and validation of a generic multisensor algorithm for mapping of total suspended matter in turbid waters. Remote Sens. Environ. 2010, 114, 854-866. [CrossRef]

5. Saad, A.; Emam, W.; El-Moselhy, K.; El-Naga, E.H.A.; Baleg, A.O. Comparative study on some heavy metals in water, sediments and fish along the Suez Canal, Egypt. Int. J. Environ. Sci. Eng. 2016, 7, $23-33$.

6. Khedr, A.I.; Soliman, Y.A.; El-Sherbeny, E.F.; Hamed, M.A.; Ahmed, M.A.; Goher, M.E. Water quality assessment of the northern part of suez gulf (Red sea, Egypt), using principal component analysis. Egypt. J. Aquat. Biol. Fish. 2019, 23, 527-538. [CrossRef] 
7. Geriesh, M.H.; Mansour, B.M.H.; Farouk, H. Assessment of drinking water quality along Port Said Canal treatment plants, Suez Canal corridor, Egypt. Arab. J. Geosci. 2019, 12, 1-13. [CrossRef]

8. Toming, K.; Kutser, T.; Laas, A.; Sepp, M.; Paavel, B.; Nõges, T. First Experiences in Mapping Lake Water Quality Parameters with Sentinel-2 MSI Imagery. Remote Sens. 2016, 8, 640. [CrossRef]

9. Niroumand-Jadidi, M.; Bovolo, F.; Bruzzone, L.; Gege, P. Inter-Comparison of Methods for Chlorophyll-A Retrieval: Sentinel-2 Time-Series Analysis in Italian Lakes. Remote Sens. 2021, 13, 2381. [CrossRef]

10. Hansen, C.; Burian, S.; Dennison, P.; Williams, G. Spatiotemporal Variability of Lake Water Quality in the Context of Remote Sensing Models. Remote Sens. 2017, 9, 409. [CrossRef]

11. Dörnhöfer, K.; Göritz, A.; Gege, P.; Pflug, B.; Oppelt, N. Water Constituents and Water Depth Retrieval from Sentinel-2A-A First Evaluation in an Oligotrophic Lake. Remote Sens. 2016, 8, 941. [CrossRef]

12. Kutser, T.; Paavel, B.; Verpoorter, C.; Ligi, M.; Soomets, T.; Toming, K.; Casal, G. Remote Sensing of Black Lakes and Using 810 nm Reflectance Peak for Retrieving Water Quality Parameters of Optically Complex Waters. Remote Sens. 2016, 8, 497. [CrossRef]

13. Ansper, A.; Alikas, K. Retrieval of Chlorophyll a from Sentinel-2 MSI Data for the European Union Water Framework Directive Reporting Purposes. Remote Sens. 2018, 11, 64. [CrossRef]

14. Niroumand-Jadidi, M.; Bovolo, F.; Bruzzone, L. Novel Spectra-Derived Features for Empirical Retrieval of Water Quality Parameters: Demonstrations for OLI, MSI, and OLCI Sensors. IEEE Trans. Geosci. Remote Sens. 2019, 57, 10285-10300. [CrossRef]

15. Dona, C.; Sanchez, J.M.; Caselles, V.; Dominguez, J.A.; Camacho, A. Empirical relationships for monitoring water quality of lakes and reservoirs through multispectral images. IEEE J. Sel. Top. Appl. Earth Obs. Remote Sens. 2014, 7, 1632-1641. [CrossRef]

16. Niroumand-Jadidi, M.; Bovolo, F.; Bruzzone, L. SMART-SDB: Sample-specific multiple band ratio technique for satellite-derived bathymetry. Remote Sens. Environ. 2020, 251, 112091. [CrossRef]

17. Hafeez, S.; Wong, M.S.; Ho, H.C.; Nazeer, M.; Nichol, J.; Abbas, S.; Tang, D.; Lee, K.H.; Pun, L. Comparison of Machine Learning Algorithms for Retrieval of Water Quality Indicators in Case-II Waters: A Case Study of Hong Kong. Remote Sens. 2019, 11, 617. [CrossRef]

18. Blix, K.; Eltoft, T.; Blix, K.; Eltoft, T. Machine Learning Automatic Model Selection Algorithm for Oceanic Chlorophyll-a Content Retrieval. Remote Sens. 2018, 10, 775. [CrossRef]

19. Niroumand-Jadidi, M.; Vitti, A.; Lyzenga, D.R. Multiple Optimal Depth Predictors Analysis (MODPA) for river bathymetry: Findings from spectroradiometry, simulations, and satellite imagery. Remote Sens. Environ. 2018, 218, 132-147. [CrossRef]

20. Niroumand-Jadidi, M.; Vitti, A. Optimal band ratio analysis of WorldView-3 imagery for bathymetry of shallow rivers (case study: Sarca River, Italy). In International Archives of the Photogrammetry, Remote Sensing and Spatial Information Sciences-ISPRS Archives; ISPRS: Hannover, Germany, 2016; Volume 41.

21. Gege, P. WASI-2D: A software tool for regionally optimized analysis of imaging spectrometer data from deep and shallow waters. Comput. Geosci. 2014, 62, 208-215. [CrossRef]

22. Niroumand-Jadidi, M.; Bovolo, F.; Bruzzone, L.; Gege, P. Physics-based Bathymetry and Water Quality Retrieval Using PlanetScope Imagery: Impacts of 2020 COVID-19 Lockdown and 2019 Extreme Flood in the Venice Lagoon. Remote Sens. 2020, 12, 2381. [CrossRef]

23. Niroumand-Jadidi, M.; Bovolo, F.; Bruzzone, L. Water Quality Retrieval from PRISMA Hyperspectral Images: First Experience in a Turbid Lake and Comparison with Sentinel-2. Remote Sens. 2020, 12, 3984. [CrossRef]

24. Niroumand-Jadidi, M.; Bovolo, F. Water Quality Retrieval and Algal Bloom Detection Using High-Resolution Cubesat Imagery. ISPRS Ann. Photogramm. Remote Sens. Spat. Inf. Sci. 2021, 3, 191-195. [CrossRef]

25. Mobley, C.D. Light and Water: Radiative Transfer in Natural Waters; Academic Press: Cambridge, MA, USA, 1994; ISBN 9780125027502.

26. Mobley, C.D.; Sundman, L.K.; Davis, C.O.; Bowles, J.H.; Downes, T.V.; Leathers, R.A.; Montes, M.J.; Bissett, W.P.; Kohler, D.D.R.; Reid, R.P.; et al. Interpretation of hyperspectral remote-sensing imagery by spectrum matching and look-up tables. Appl. Opt. 2005, 44, 3576-3592. [CrossRef] [PubMed]

27. Brockmann, C.; Doerffer, R.; Peters, M.; Stelzer, K.; Embacher, S.; Ruescas, A. Evolution of the C2RCC neural network for Sentinel 2 and 3 for the retrieval of ocean colour products in normal and extreme optically complex waters. In Proceedings of the Living Planet Symposium 2016, Prague, Czech Republic, 9-13 May 2016; pp. 9-13.

28. BBC. Suez Canal: Ever Given Container Ship Shifted from Shoreline-BBC News. Available online: https://www.bbc.com/news/ world-middle-east-56559904 (accessed on 6 April 2021). 